\title{
O-Sr (Oxygen-Strontium)
}

\section{H. Okamoto}

Figure 1 shows the $\mathrm{Sr}-\mathrm{O}$ phase diagram at 1 bar total pressure calculated by [96Ris]. Crystal structure data (Table 1) are from [56Swa]. [Massalski2] quoted the melting point of SrO at $2420^{\circ} \mathrm{C}$ from [63Sch]. [96Ris] accepted a much higher temperature in Fig. 1 from [69Nog].

\section{Cited References}

56Swa: H.E. Swanson, N.T. Gilfrich, and G.M. Ugrinic, NBS Circ., 539 (1956).

63Sch: S.J. Schneider, NBS Monograph 68, 31 pages (1963).

69Nog: T. Noguchi, Advances in High Temperature Chemistry, L.

Eyring, Ed., Vol. 2, Academic Press, New York, 235-262 (1969).

96Ris: D. Risold, B. Hallstedt, and L.J. Gauckler, Calphad, 20(3), 353361 (1996).

Table 1 Sr-O Crystal Structure Data

\begin{tabular}{|c|c|c|c|c|c|}
\hline Phase & $\begin{array}{c}\text { Composition, } \\
\text { at. } \% 0\end{array}$ & $\begin{array}{l}\text { Pearson } \\
\text { symbol }\end{array}$ & $\begin{array}{l}\text { Space } \\
\text { group }\end{array}$ & $\begin{array}{c}\text { Strukturbericht } \\
\text { designation }\end{array}$ & Prototype \\
\hline$(\mathrm{BSr})$ & 0 & $c D$ & $I m \overline{3} m$ & $A 2$ & w \\
\hline 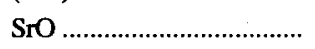 & 50 & $c F 8$ & $F m \overline{3} m$ & $B 1$ & $\mathrm{NaCl}$ \\
\hline $\mathrm{SrO}_{2}$ & 66.7 & $t 16$ & $14 / \mathrm{mmm}$ & $C 11_{\mathrm{a}}$ & $\mathrm{CaC}_{2}$ \\
\hline
\end{tabular}

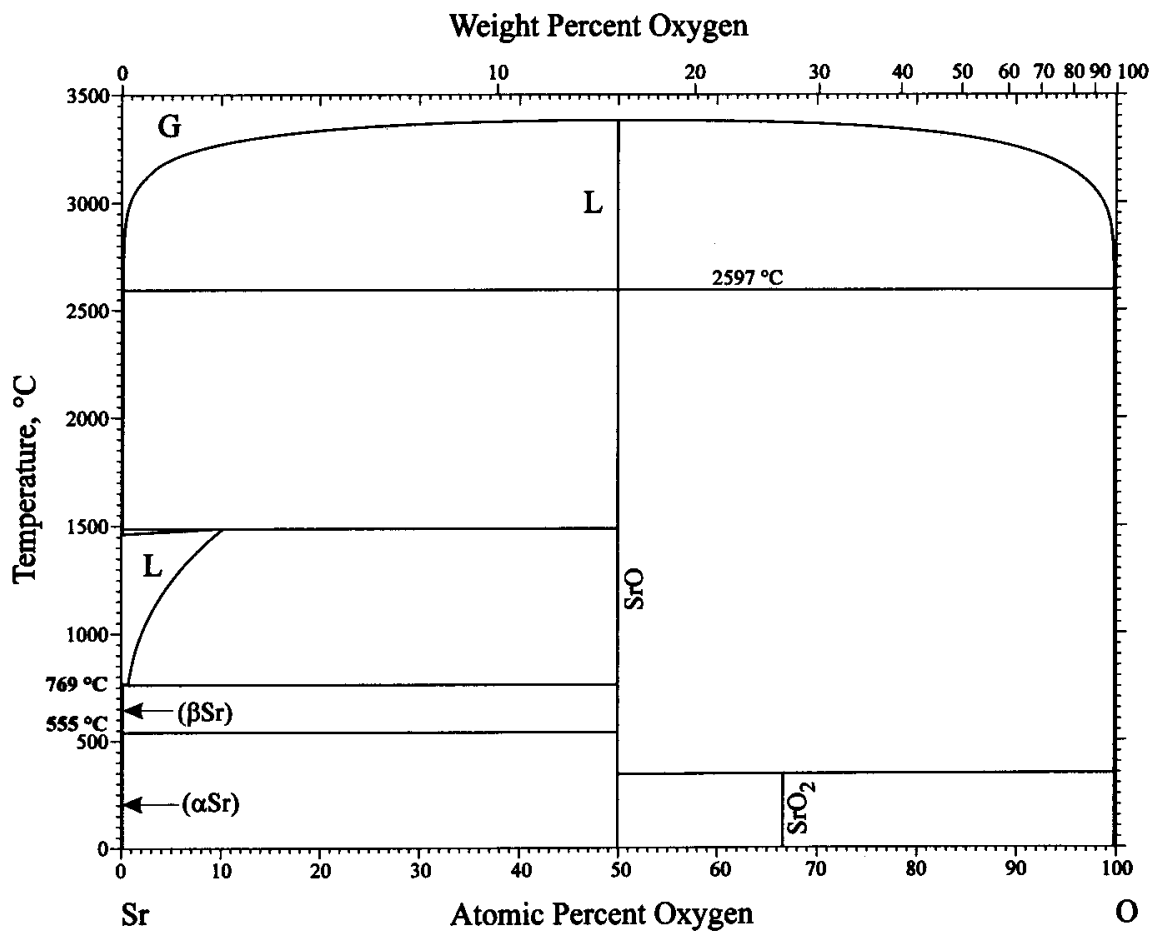

Fig. 1 The $\mathrm{Sr}-\mathrm{O}$ phase diagram. 